\title{
Flake-shaped rice bodies
}

\section{J R Kichari, R Bezooijen}

Department of Radiology, Medisch Spectrum Twente, Enschede, The Netherlands

J R Kichari, MD

R Bezooijen, MD

Corresponding author: J Kichari (J.Kichari@mst.nl)

Rice body formation is a common complication of rheumatoid arthritis but can also occur without any underlying systemic disorder. MRI is the modality of choice for discriminating this pathology from synovial chondromatosis.

S Afr J Rad 2012;16(4):140-141. DOI:10.7196/SAJR.725

A 47-year-old man was examined because of a 2-month history of a non-painful swelling of the right shoulder. Physical examination showed a non-tender mass over the right deltoid region and a normal range of movement. Laboratory findings were unremarkable. The shoulder radiograph demonstrated a soft tissue mass in the deltoid region without calcifications or erosions. Ultrasound showed numerous flake-shaped lesions (Fig. 1). After radiography and ultrasound, the differential diagnosis was rice body formation or synovial chondromatosis. Subsequent MRI demonstrated numerous flake-shaped lesions, iso-intense on T1- and T2-weighted images with clear delineation of the flake-shaped lesions on the T2-weighted images (Fig. 2). The flake-shaped lesions showed no enhancement after intravenous gadolinium. The bursa wall was thickened, with marked enhancement representing bursitis. At surgery, the bursa and numerous flake-shaped lesions were resected. The pathological appearances were consistent with rice bodies. The patient recovered well and, at one-year follow-up, no underlying disorder was identified.

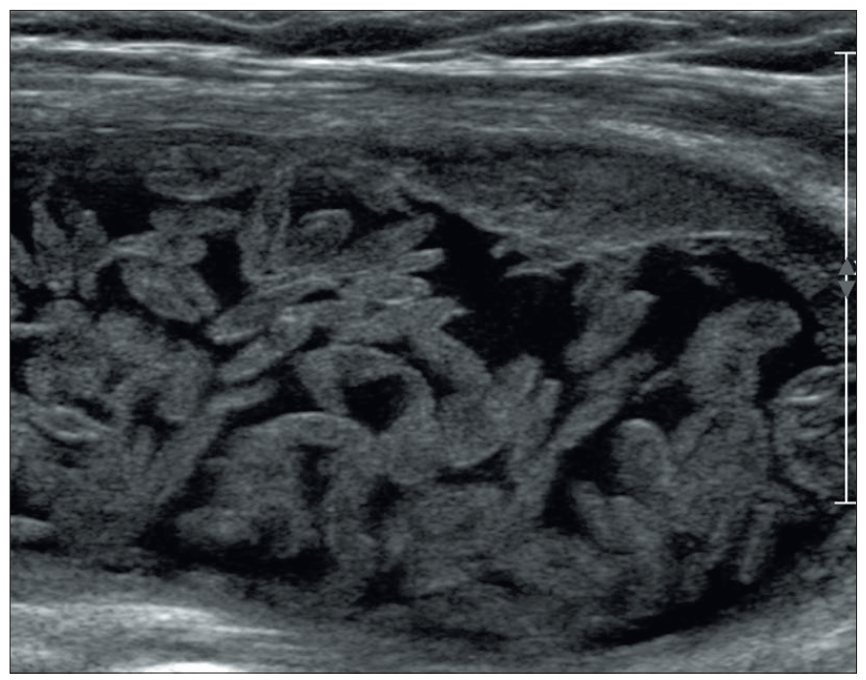

Fig. 1. Ultrasound (linear $12 \mathrm{MHz}$ transducer) of the left shoulder shows numerous well-defined iso-echoic oval lesions with no acoustic shadowing in a distended subacromial-subdeltoid bursa. There was marked bursa wall thickening and a moderate amount of hypoechoic fluid.

\section{Discussion}

The aetiology of rice body formation is still unknown. Cheung et al. suggested synovial origin with micro-infarction of synovial cells after inflammation and ischaemia, ${ }^{1}$ whereas Popert et al. proposed a de novo formation of rice bodies in synovial fluid independently of synovial elements. ${ }^{2}$

Formation of rice bodies has been reported in joints, ${ }^{1,2}$ bursae ${ }^{3-6}$ and tendon sheaths, ${ }^{5}$ and are commonly observed in chronic rheumatoid arthritis, seronegative inflammatory arthritis and tuberculous joints. ${ }^{3}$ Different-shaped rice bodies are described, varying from nodules and teardrops to angular and flake-shaped with variable sizes. ${ }^{4,5}$

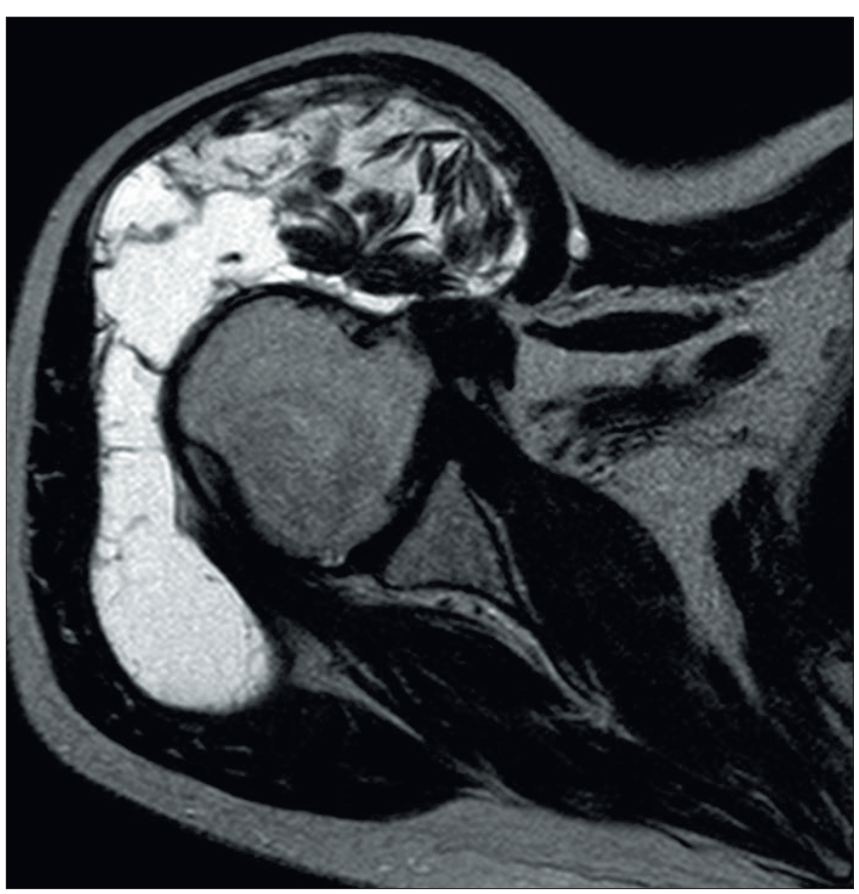

Fig. 2. Axial T2-weighted image of the right shoulder shows numerous welldelineated oval nodules with an iso-intense signal intensity relative to skeletal muscle and a large amount of bursa fluid in a markedly distended subacromialsubdeltoid bursa. 


\section{PICTORIAL INTERLUDES}

On MRI, rice bodies have been described as having iso- or hypointense signal intensities relative to skeletal muscle on T1- and T2-weighted images, and the rice bodies were less discernible from the surrounding bursa fluid on T1-weighted image and clearly discernible on T2-weighted image. ${ }^{3-5}$

Synovial chondromatosis was a differential diagnosis in the above case. Synovial chondromatosis usually has an iso-intense or slightly hyperintense signal intensity on T1-weighted image, and hyperintense signal intensity on $\mathrm{T} 2$-weighted image relative to the signal intensity of skeletal muscles. Hence, differentiation of the unmineralised nodules in synovial chondromatosis from surrounding fluid on both sequences is difficult, whereas rice bodies can clearly be differentiated from surrounding fluid on T2-weighted image. ${ }^{3,5,6}$ Treatment consists of removing the rice bodies and the bursa. ${ }^{3}$
In summary: rice bodies can occur without underlying systemic disorder, have different shapes and sizes, and have specific signal characteristics on MRI that allow discrimination from synovial chondromatosis.

1. Cheung HS, Ryan LM, Kozin F, McCarty DJ. Synovial origins of rice bodies in joint fluid. Arthritis Rheum 1980;23:72-76.

2. Popert AJ, Scott DL, Wainwright AC, Walton KW, Williamson N, Chapman JH. Frequency of occurrence, mode of development, and significance of rice bodies in rheumatoid joints. Ann Rheum Dis 1982;41:109-117.

3. Chen A, Wong LY, Sheu CY, Chen BF. Distinguishing multiple rice body formation in chronic subacromial-subdeltoid bursitis from synovial chondromatosis. Skeletal Radiol 2002;31:119-121.

4. Law TC, Chong SF, Lu PP, Mak KH. Bilateral subacromial bursitis with macroscopic rice bodies: Ultrasound, CT and MR appearance. Australas Radiol 1998;42(2):161-163.

5. Sugano I, Nagao T, Tajima Y, et al. Variation among giant rice bodies: report of four cases and their clinicopathological features. Skeletal Radiol 2000;29(9):525-529.

6. Griffith JF, Peh WC, Evans NS, Smallman LA, Wong RW, Thomas AM. Multiple rice body formation in chronic subacromial/subdeltoid bursitis: MR appearances. Clin Radiol 1996;51(7):511. 